Article

\title{
The Efficacy of Bamboo Charcoal in Comparison with Smectite to Reduce the Detrimental Effect of Aflatoxin B1 on In Vitro Rumen Fermentation of a Hay-Rich Feed Mixture
}

\author{
Ya-Hui Jiang ${ }^{1}$, Ping Wang ${ }^{2}$, Hong-Jian Yang ${ }^{1, *}$ and Ying Chen ${ }^{2}$
}

1 State Key Laboratory of Animal Nutrition, College of Animal Science and Technology, China Agricultural University, Beijing 100193, China; E-Mail: jiangyahui.ff@163.com

2 Agro-product Safety Research Centre, Chinese Academy of Inspection and Quarantine, Beijing 100123, China; E-Mails: wangp_129@163.com (P.W.); chenyingcaiq@163.com (Y.C.)

* Author to whom correspondence should be addressed; E-Mail: yang_hongjian@cau.edu.cn; Tel.: +86-10-6273-3124; Fax: +86-10-6273-4859.

Received: 24 April 2014; in revised form: 20 June 2014 / Accepted: 3 July 2014 /

Published: 10 July 2014

\begin{abstract}
Two commercial materials, a bamboo charcoal (BC) and a smectite clay (SC), were assessed in vitro with aflatoxin B1 (AFB1) in an equilibrium adsorption test. The adsorption capacity and proportion adsorbed $(0.381 \mu \mathrm{g} / \mathrm{mg}, 0.955)$ for $\mathrm{BC}$ were greater than for SC $(0.372 \mu \mathrm{g} / \mathrm{mg}, 0.931)$. The effects of in vitro ruminal fermentation of hay-rich feed incubated with $1.0 \mu \mathrm{g} / \mathrm{mL}$ AFB1 for $0-10 \mathrm{~g} / \mathrm{L}$ doses of BC and SC were measured at $39{ }^{\circ} \mathrm{C}$ for $72 \mathrm{~h}$. The BC and SC binders increased AFB1 loss at dosages $\geq 1.0 \mathrm{~g} / \mathrm{L}$ $(p<0.0001)$. Average AFB1 loss $(p<0.0001)$ was greater for SC $(0.904)$ than $\mathrm{BC}(0.881)$. Both SC and SC addition increased in vitro dry matter loss, and the average dry matter losses were similar. Asymptotic gas volume and volatile fatty acid production were greater for $\mathrm{BC}$ than for SC $(p<0.0001)$. Thus, BC may be as effective as $\mathrm{SC}$ in removing aflatoxin B1's detrimental effects on rumen degradability and fermentation under the occurrence of microbial aflatoxin degradation.
\end{abstract}

Keywords: bamboo charcoal; smectite clay; aflatoxin B1; rumen fermentation; in vitro 


\section{Introduction}

Aflatoxin B1 (AFB1), a toxin produced by Aspergillus flavus or Aspergillus parasiticus fungi, is highly mutagenic and carcinogenic to animals [1]. The transfer rates from dietary AFB1 to aflatoxin M1 in milk have been reported to be $0.01-0.02$ [2], and the carry over rate is positively related with the milk yield when large amounts of contaminated concentrate are consumed [3]. Aflatoxin contaminants in feeds fed to ruminants are more problematic than other mycotoxins, because they are only partially degraded by rumen microorganisms [4]. Over the years, various methods, including chemical (e.g., ammoniation, alkalization), physical (e.g., activated charcoal, bentonite and hydrated sodium calcium aluminosilicate (HSCAS)) and biological (e.g., bacteria, yeasts, fungi and enzymes) processes, have been proposed and tested as tools to overcome AFB1 contamination in food and feeds [5]. Among the physical methods to control mycotoxin toxicity, smectite-containing products are made from naturally variable montmorillonite or bentonite clays that have high in vitro aflatoxin adsorption capacity and are wildly recommended, though the data of the demonstrated in vivo product efficacy have been limited until now [6,7]. Bamboo is a renewable, readily available forest resource in China and many other Asian countries. It can be harvested with little damage to sensitive ecosystems, due to its rapid growth rate (1-4 cm/h during the fertile period). The many pores make bamboo charcoal an excellent adsorbent, and it has been widely used in, e.g., medicines, cosmetics and food processing [8]. However, no literature has been found that has assessed the adsorption capacity of bamboo charcoal as an alternative sequestering agent for binding mycotoxins.

The high cost and health risk of the in vivo testing of aflatoxin enterosorbents in farm animals calls for valid in vitro methods for the selection of potentially useful sorbents for subsequent in vivo studies. Several in vitro methods have been developed to study AFB1 binding by sorbents. For instance, Lemke et al. [9] reported a multi-tiered approach that simulated the digestive process in non-ruminants, and Spotti et al. [10] developed a very low-cost, simple and rapid way to evaluate the in vitro adsorptive ability of a binder in ruminant animals. The authors' previous study noted that the in vitro rumen microbial activity declined with the increase of the AFB1 dosage in cultural fluids [11]. The effect was more pronounced for a hay-rich diet than for a maize-rich diet. The applicability of different binders is to bind dietary mycotoxins and reduce their absorption in the gastrointestinal tract of animals [12]. In the present study, a smectite clay product was chosen as an aluminosilicate containing reference binder with a high adsorbing capacity for aflatoxin [6,7], and the objective was to compare bamboo charcoal with the selected smectite clay with respect to AFB1 adsorption capacity and the ability to reduce the detrimental effects of AFB1 on rumen fermentation.

\section{Methods}

\subsection{Binders}

A bamboo charcoal (BC) was gifted by the Suichang Biyan Bamboo Charcoal Company Ltd. (Suichang, Zhejiang, China). The quality-labeled product contained $850-880 \mathrm{~g} / \mathrm{kg}$ carbon and 20-40 g/kg ash, as indicated by the manufacturer. The selected smectite clay (SC) was a commercial product named ConditionAde ${ }^{\mathrm{TM}} 200 \mathrm{HPC}$ (Oil-Dri Co. Ltd., Chicago, IL, USA), and it contained $450-650 \mathrm{~g} / \mathrm{kg}$ of smectite, as guaranteed by the product. All of these products were dried at $65{ }^{\circ} \mathrm{C}$ 
for $24 \mathrm{~h}$ and ground to pass a 2.0-mm sieve, and their density, specific surface area and pore volume are in Table 1.

Table 1. Physical characteristics of two quality-labeled binders used in the Experiments 1 and 2.

\begin{tabular}{cccc}
\hline Binder & Density $\left(\mathbf{k g} / \mathbf{m}^{3}\right)$ & Surface area $\left(\mathbf{m}^{2} / \mathbf{g}\right)$ & Pore volume $\left(\mathbf{c m}^{3} / \mathbf{g}\right)$ \\
\hline Smectite clay & 618 & 115 & 0.296 \\
Bamboo charcoal & 800 & 300 & 0.300 \\
\hline
\end{tabular}

In Experiment 1, an in vitro AFB1 binding equilibrium test was conducted to determine the adsorption capacity and proportion of each binder, assuming that the amount of binder relative to toxin is not a limiting factor. Since demonstrated significant in vitro binding capacity might not correlate directly with significant biological efficacy, batch cultures to mimic the rumen environment in Experiment 2 were done to determine the efficacy of $\mathrm{BC}$ in comparison with SC to reduce the detrimental effect of AFB1 on the rumen fermentation of a hay-rich feed mixture.

\subsection{Adsorption Capacity and Adsorption Proportion of Two Binders for the Binding of Aflatoxin B1 (Experiment 1)}

\subsubsection{Experimental Design}

Under the presence of $4 \mathrm{mg} / \mathrm{L} \mathrm{AFB} 1$ in culture fluids, $\mathrm{BC}$ and $\mathrm{SC}$ with the addition level of $10 \mathrm{~g} / \mathrm{L}$ in a buffer $(\mathrm{pH}$ 6.85) [13] were assessed in vitro for their adsorption capacity and adsorption proportion for the mycotoxin after 3, 6, 12, 24, 48 and $72 \mathrm{~h}$ incubation. Within each binder, there were five replicates for each incubation time.

\subsubsection{In Vitro Incubation and Sampling Procedure}

The buffer was freshly prepared, bubbled and saturate with $\mathrm{CO}_{2}$ until the $\mathrm{pH}$ reached 6.85 prior to the incubation. Following the aflatoxin binding equilibrium test method of Vekiru et al. [14], $50 \mathrm{mg}$ of $\mathrm{SC}$ or $\mathrm{BC}$ binders were individually weighed into $10-\mathrm{mL}$ volume culture tubes containing $5.0 \mathrm{~mL}$ of the buffer. Afterwards, $0.1 \mathrm{~mL}$ of a working solution of AFB1 (Alexis Corporation, San Diego, CA, USA) dissolved in methanol were added to the tubes, resulting in final concentrations of $4 \mu \mathrm{g} / \mathrm{mL}$ AFB1 and $10 \mathrm{~g} / \mathrm{L}$ binder, in accordance with the reference levels [15]. Meanwhile, $0.1 \mathrm{~mL}$ methanol were added to AFB1-free blank tubes with the addition of BC or SC. The whole experiment was completed in two batch cultures at a one day interval. The tubes incubated at $39{ }^{\circ} \mathrm{C}$ were gently agitated and removed at 3,12 and $48 \mathrm{~h}$ in the first batch, and the rest of the tubes were done at 6, 24 and $72 \mathrm{~h}$ in the second batch. After the removal, the tubes were vortexed and immediately centrifuged at $10,000 \times \mathrm{g}$ for $10 \mathrm{~min}$ at room temperature, and the supernatants were collected. The pellets were resuspended two times in $5 \mathrm{~mL}$ methanol by vortexing for $30 \mathrm{~s}$ and shaking at $39{ }^{\circ} \mathrm{C}$ for $1 \mathrm{~h}$. All three supernatants were pooled together for later AFB1 analyses to calculate the adsorption capacity and proportion. 


\subsection{Animals and Rumen Fluid Collection}

Three lactating multiparous Holstein cows, fitted with ruminal cannulas (Type 2C: Bar Diamond Inc., Parma, ID, USA), served as donor animals for rumen fluid collection in the later Experiment 2. The cows were fed daily $40 \mathrm{~kg}$ of a total mixed ration (Table 2) with a moisture content of $480 \mathrm{~g} / \mathrm{kg}$ as fed, and the ration was divided into 2 equal portions offered at 06:00 and 18:00. The rumen fluids $(700 \mathrm{~mL})$, collected from each animal $2 \mathrm{~h}$ after the morning feeding, were squeezed through four layers of cheesecloth and mixed in equal proportion. The mixed rumen fluid was then transferred into a thermos pre-warmed at $39^{\circ} \mathrm{C}$ and served as the inocula for the later batch culture.

Table 2. Ingredients and chemical composition of the ration fed to cows.

\begin{tabular}{cc}
\hline Items & Value \\
\hline Ingredients $(\mathrm{g} / \mathrm{kg} D M)$ & \\
\hline Corn silage & 250 \\
Chinese wildrye grass hay & 167 \\
Alfalfa hay & 83 \\
Corn meal & 267 \\
Soybean meal & 138 \\
Wheat bran & 69 \\
Limestone & 11 \\
Calcium phosphate & 6.1 \\
Salt & 4.4 \\
Premix ${ }^{\dagger}$ & 4.5 \\
\hline Nutrients & 6.69 \\
\hline Crude protein $(\mathrm{g} / \mathrm{kg} \mathrm{DM})$ & 160 \\
Neutral detergent fiber $(\mathrm{g} / \mathrm{kg} \mathrm{DM})$ & 382 \\
Acid detergent fiber $(\mathrm{g} / \mathrm{kg} \mathrm{DM})$ & 225 \\
\hline
\end{tabular}

Note: ${ }^{\dagger}$ The trace mineral and vitamin premix contained $\mathrm{Cu} 3 \mathrm{~g} / \mathrm{kg}, \mathrm{Zn} 12 \mathrm{~g} / \mathrm{kg}, \mathrm{Mn} 4.8 \mathrm{~g} / \mathrm{kg}, \mathrm{Fe} 10 \mathrm{~g} / \mathrm{kg}$, Co $0.2 \mathrm{~g} / \mathrm{kg}$, I $0.1 \mathrm{~g} / \mathrm{kg}$, Se $0.1 \mathrm{~g} / \mathrm{kg}$, vitamin A $1000 \mathrm{IU} / \mathrm{g}$, vitamin D3 $250 \mathrm{IU} / \mathrm{g}$, vitamin E $10 \mathrm{IU} / \mathrm{g}$ and vitamin B3 $5 \mathrm{mg} / \mathrm{g}$.

2.4. Effect of BC and SC on In Vitro Rumen Fermentation of a Hay-Rich Feed in the Presence of AFB1 (Experiment 2)

\subsubsection{Preparation of a Hay-Rich Feed}

Chinese wildrye grass (Leymus chinensis) hay prepared at the late-bloom stage was chopped (2-5 $\mathrm{mm}$ ), dried at $65{ }^{\circ} \mathrm{C}$ overnight in a forced air oven and ground in a Wiley mill to pass a 2.0-mm sieve. Maize meal $(2 \mathrm{~mm})$, stored in the laboratory, was mixed with the chopped hay in a 1:4 ratio to make a hay-rich substrate. The chemical composition (calculated per $\mathrm{kg} \mathrm{DM}$ ) of the hay-rich feed was: $133 \mathrm{~g}$ crude protein, $565 \mathrm{~g}$ neutral detergent fiber, $312 \mathrm{~g}$ acid detergent fiber and $54 \mathrm{~g}$ ash. 


\subsubsection{Experimental Design}

A completely randomized block design was applied to determine the effect of $\mathrm{BC}$ in comparison with SC at four doses (0 (control), 0.1, $1,10 \mathrm{~g} / \mathrm{L}$ ) on in vitro ruminal fermentation of the hay-rich substrate in the presence of $1.0 \mu \mathrm{g} / \mathrm{mL}$ AFB1. Meanwhile, the methanol negative controls included the substrate, but no binder or AFB1. For each treatment were arranged four fermentations, and the batch culture was repeated in three runs.

\subsubsection{In Vitro Ruminal Batch Cultures}

Briefly, $500 \mathrm{mg}$ of the substrate were weighed into $120-\mathrm{mL}$ bottles containing $7.5,75$ or $750 \mathrm{mg}$ of the binders. To each bottle were added $25 \mathrm{~mL}$ of the filtered rumen fluid, $49 \mathrm{~mL}$ of the buffer [13], as noted in Experiment 1, and $1.0 \mathrm{~mL}$ of the aflatoxin working solution of $75 \mathrm{mg}$ AFB1 dissolved in $1 \mathrm{~L}$ methanol, purged with $\mathrm{N}_{2}$ for $5 \mathrm{~s}$ to remove air in the bottle's headspace. Methanol $(1.0 \mathrm{~mL})$ was added to the negative control bottles with the substrate. All bottles were sealed with butyl rubber stoppers and Hungate's screw-caps. A one-off use transfusion needle was inserted into bottles through the stopper, and its pipe was immediately connected to each gas inlet of the automated gas production recording system (AGRS, Beijing, China) [16]. All bottles were incubated at $39{ }^{\circ} \mathrm{C}$ for $72 \mathrm{~h}$. Substrate-free blank bottles containing buffer, ruminal fluid and AFB1 were run simultaneously to correct difference between the runs of batch culture due to variation in rumen fluid preparation.

\subsubsection{Gas Production and Curve Fitting}

The cumulative gas production values (GP, $\mathrm{mL} / \mathrm{g}$ dry matter), exported from the automated gas production recording system, were fitted with time (t) to the exponential model [17] as Equation (1):

$$
G P=b \times\left[1-e^{-c \times(\text { time }- \text { Lag })}\right]
$$

where $b$ is the asymptotic gas production; $c$ is the gas production rate; and $t$ is the gas recording time. The parameters $b, c$ and $L a g$ were estimated by an iterative least squares procedure using the NLIN procedure of the Statistical Software Package for Windows (version 9.02, 1999; SAS Institute Inc., Cary, NC, USA). The average gas production rate (AGPR, $\mathrm{mL} / \mathrm{h}$ ) [18] was calculated to obtain the rate between the start of the incubation and the time at which the cumulative gas production was half of its asymptotic value with Equation (2):

$$
A G P R=\frac{b \times c}{2 \times(\operatorname{Ln} 2+c \times \operatorname{Lag})}
$$

\subsubsection{Sampling Procedure and Digestibility Determination}

After the incubation, the $\mathrm{pH}$ in the culture fluids was measured immediately, and the whole biomass culture $(75 \mathrm{~mL})$ in each bottle was removed from the bottles to $100 \mathrm{~mL}$ tubes and centrifuged at $10,000 \times g$ for $15 \mathrm{~min}$ at $4{ }^{\circ} \mathrm{C}$. The supernatants were sampled later for ammonia $\mathrm{N}$ and volatile fatty acid (VFA) analyses and AFB1 analysis to estimate the mycotoxin disappearance rate. The pellets remaining in the tubes were resuspended in $75 \mathrm{~mL}$ pure methanol solution, agitated and washed at $39{ }^{\circ} \mathrm{C}$ for $1 \mathrm{~h}$ to partially remove AFB1, presumably not incorporated into the adsorbent-AFB1 complexes. Afterwards, 
the tubes were then centrifuged at $10,000 \times g$ for $15 \mathrm{~min}$, and these supernatants from the above washes were sampled for later analysis of the residual AFB1 concentration to estimate the recovered quantity of AFB1 that would not be detoxified, but that would be bound to the hay-rich feed and binders in the system. The whole residual pellets were dried at $105{ }^{\circ} \mathrm{C}$ to a constant weight. In vitro dry matter disappearance (IVDMD) was calculated as the dry matter (DM) loss, represented as the difference between the original incubated DM and the residual DM, corrected by blanks [16].

\subsection{Chemical Analysis and Calculations}

Representative samples of the hay and maize meal were analyzed, respectively, following the standard method [19] for DM (ID 930.5), crude protein (ID 984.13) and ash (ID 942.05). Neutral detergent fiber and acid detergent fiber contents were analyzed [20] and expressed without residual ash.

Following the method of Upadhaya et al. [21], $0.3 \mathrm{~mL}$ of the supernatant samples in Experiments 1 and 2 were added to $1.5-\mathrm{mL}$ Eppendorf tubes and mixed thoroughly with $0.7 \mathrm{~mL}$ methanol. The extracted AFB1 samples were immediately diluted to a final methanol concentration of $70 \%(\mathrm{v} / \mathrm{v})$ with deionized water. The concentration of AFB1 in the sample extracts was determined at $490 \mathrm{~nm}$ with an AFB1 enzyme-linked immunoassay test kit (Brins-livePro Biotechnology Co., Ltd., Beijing, China). All chemical analyses were done in triplicate.

Ammonia $\mathrm{N}$ concentration in the supernatant samples resulting from the first centrifugation in Experiment 2 was measured at $637 \mathrm{~nm}$ [22]. The supernatant samples (1 mL) were mixed with $0.3 \mathrm{~mL}$ of $250 \mathrm{~g} / \mathrm{L}$ meta-phosphoric acid solution for $30 \mathrm{~min}$ and centrifuged at $10,000 \times \mathrm{g}$ for $15 \mathrm{~min}$ at $4{ }^{\circ} \mathrm{C}$. The concentrations of acetate, propionate, butyrate, iso-butyrate, valerate and iso-valerate in the supernatants were measured by a gas chromatography (GC522, Wufeng Instruments, Shanghai, China). The ratio of non-glucogenic to glucogenic acids (NGR) [23] was calculated as Equation (3):

$$
N G R=\frac{\text { Acetate }+2 \times \text { Butyrate }+ \text { Valerate }}{\text { Propionate }+ \text { Valerate }}
$$

where VFAs were expressed in molar proportions of total volatile fatty acid production.

\subsection{Statistical Analysis}

Data in Experiment 1 consisted of 2 binders, 6 incubation times and 5 fermentations, making a total of 60 observations, and these were analyzed using a general linear model in which the fixed effects of binder and incubation time were considered. Data in Experiment 2 consisted of 1 control, the 3-dose level of each binder of SC and BC, 4 fermentations and 3 runs, making a total of 84 observations, and the statistical analyses were performed using a general linear model in which the fixed effects of binder and dosage were considered. All of the analyses were performed using the statistical software package for Windows (version 9.02, 1999; SAS Institute Inc., Cary, NC, USA). Least squares means and standard errors (SEM) for the measured variables were calculated. The means within each binder were compared using a multiple comparison test (Tukey), and orthogonal contrasts were used to assess the difference between SC and BC. Significance was declared at $p<0.05$, unless otherwise noted. 


\section{Results}

\subsection{Experiment 1}

Neither the adsorption capacity nor the proportion differed in response to incubation time (Figure 1), but they were comparatively higher in $\mathrm{BC}$ than in SC.

Figure 1. The adsorption capacity (a) and proportion (b) of smectite clay (SC) and bamboo charcoal (BC) for binding aflatoxin B1 (AFB1) in vitro at different incubation times (Experiment 1).

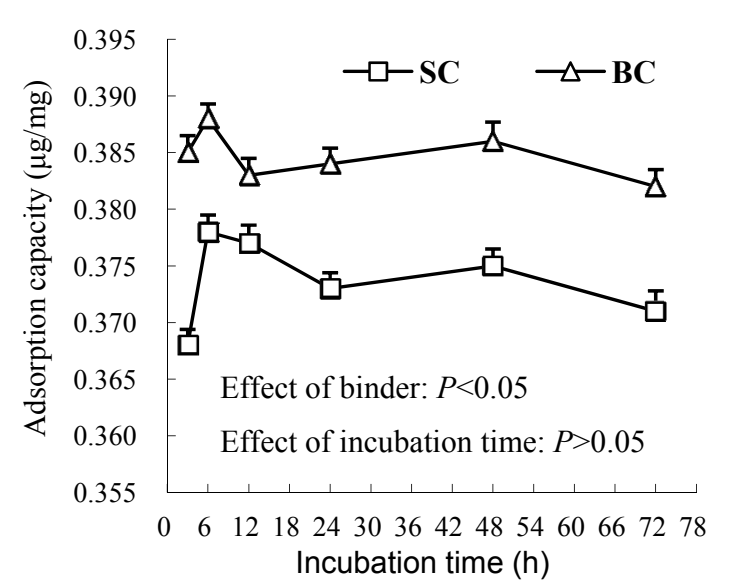

(a)

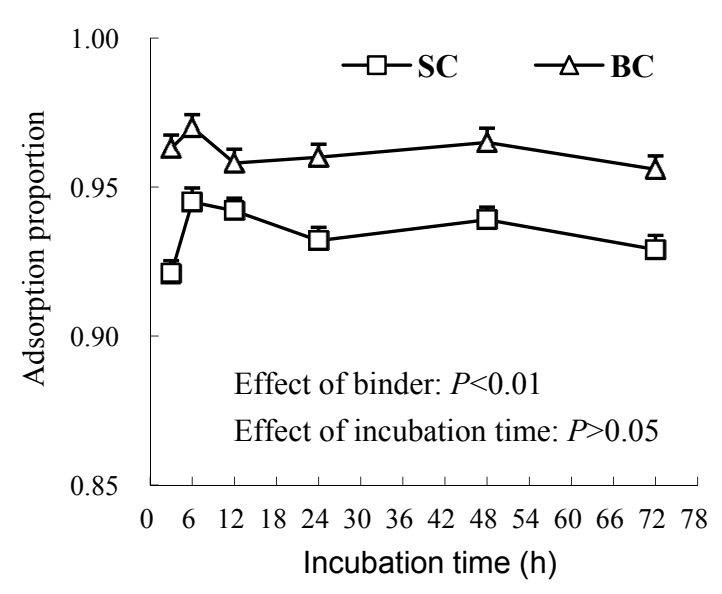

(b)

Notes: Aflatoxin adsorption capacity (a) was calculated as $\left(C_{0}-C_{e q}\right) \times \mathrm{V} / \mathrm{m}$; and the aflatoxin adsorption proportion (b) was calculated as $\left(C_{0}-C_{e q}\right) / C_{0}$, in which $C_{0}$ is the initial concentration of AFB1 $(4 \mu \mathrm{g} / \mathrm{mL})$ spiked in the buffer; $C_{e q}$ is the residual AFB1 $(\mu \mathrm{g} / \mathrm{mL})$ recovered from the pellets after the methanol washing and centrifuging procedure; $V$ is the volume of incubation system $(\mathrm{mL}) ; m$ is the mass weight $(\mathrm{mg})$ of each binder.

\subsection{Experiment 2}

As shown in Table 3, IVDMD increased against the addition of SC $(p=0.048)$ and BC $(p<0.0001)$, but no differences occurred for IVDMD between two binders (Table 2). Cumulative gas production at $72 \mathrm{~h}(p<0.05)$ and asymptotic gas production $(p<0.0001)$ increased when a concentration greater than or equal to $1.0 \mathrm{~g} / \mathrm{L}$ was applied for both binders. The asymptote was greater in $\mathrm{BC}$ than $\mathrm{SC}$ treatments $(p<0.0001)$. The parameter c value was decreased by the $\mathrm{SC}$ dosage of $10 \mathrm{~g} / \mathrm{L}(p=0.0006)$ and the high $\mathrm{BC}$ dosages $(\geq 1 \mathrm{~g} / \mathrm{L}, p<0.0001)$, and it was lower in the $\mathrm{BC}$ than in the $\mathrm{SC}$ treatments $(p<0.0001)$. Both SC $(p=0.0001)$ and $\mathrm{BC}(p<0.0001)$ additions decreased the fermentation lag time. The addition of $\mathrm{SC}$ or $\mathrm{BC}$ did not alter AGPR values compared to the value in the control. No differences in lag time and AGPR were observed between two binders.

AFB1 disappearance (Table 4) was increased by the addition of SC or BC at a dose level $\geq 1.0 \mathrm{~g} / \mathrm{L}$ $(p<0.0001)$, and it was greater in SC than $\mathrm{BC}(p<0.0001)$. Neither SC nor BC treatments altered $\mathrm{AFB} 1$ recovery, but the recovery value was greater in $\mathrm{BC}$ than $\mathrm{SC}$ addition treatments $(p=0.035)$. 
Table 3. The effect of different doses of bamboo charcoal in comparison with smectite clay on in vitro dry matter disappearance (IVDMD) and gas production (GP) of a hay-rich feed in the presence of $1.0 \mu \mathrm{g} / \mathrm{mL}$ aflatoxin B1 (Experiment 2).

\begin{tabular}{|c|c|c|c|c|c|c|c|c|c|c|c|c|c|c|}
\hline \multirow{2}{*}{ Items } & \multirow{2}{*}{ NC * } & \multicolumn{4}{|c|}{ Smectite clay } & \multirow{2}{*}{ SEM * } & \multirow{2}{*}{$p$-value } & \multicolumn{4}{|c|}{ Bamboo charcoal } & \multirow{2}{*}{ SEM * } & \multirow{2}{*}{$p$-value } & \multirow{2}{*}{ Contrast $^{\S}$} \\
\hline & & Control $^{\dagger}$ & $0.1 \mathrm{~g} / \mathrm{L}$ & $1 \mathrm{~g} / \mathrm{L}$ & $10 \mathrm{~g} / \mathrm{L}$ & & & Control $^{\dagger}$ & $0.1 \mathrm{~g} / \mathrm{L}$ & $1 \mathrm{~g} / \mathrm{L}$ & $10 \mathrm{~g} / \mathrm{L}$ & & & \\
\hline IVDMD (g/kg DM) & 604 & $550^{\mathrm{b}}$ & $586^{\mathrm{a}, \mathrm{b}}$ & $593^{\mathrm{a}}$ & $599^{\mathrm{a}}$ & 11.9 & 0.048 & $550^{\mathrm{b}}$ & $576^{\mathrm{a}, \mathrm{b}}$ & $589^{\mathrm{a}}$ & $594^{\mathrm{a}}$ & 7.8 & $<0.0001$ & 0.184 \\
\hline $\mathrm{GP}$ at $72 \mathrm{~h}(\mathrm{~mL} / \mathrm{g} \mathrm{DM})$ & 208.4 & $147.0^{\mathrm{b}}$ & $151.0^{b}$ & $169.1^{\mathrm{a}, \mathrm{b}}$ & $183.2^{\mathrm{a}}$ & 6.86 & 0.021 & $147.0^{\mathrm{b}}$ & $148.0^{\mathrm{b}}$ & $179.3^{\mathrm{a}}$ & $193.2^{\mathrm{a}}$ & 6.20 & 0.0014 & 0.366 \\
\hline \multicolumn{15}{|l|}{ Fermentation kinetics $\#$} \\
\hline $\mathrm{GP}_{\max }(\mathrm{mL} / \mathrm{g} \mathrm{DM})$ & 209.1 & $186.7^{c}$ & $193.8^{\mathrm{c}}$ & $240.4^{b}$ & $282.9^{\mathrm{a}}$ & 6.60 & $<0.0001$ & $186.7^{\mathrm{c}}$ & $182.5^{\mathrm{c}}$ & $270.2^{b}$ & $315.9^{\mathrm{a}}$ & 10.77 & $<0.0001$ & $<0.0001$ \\
\hline $\mathrm{c}(/ \mathrm{h})$ & 0.085 & $0.021^{\mathrm{a}}$ & $0.020^{\mathrm{a}}$ & $0.020^{\mathrm{a}}$ & $0.012^{b}$ & 0.0010 & 0.0006 & $0.021^{\mathrm{a}}$ & $0.020^{\mathrm{a}}$ & $0.015^{b}$ & $0.007^{c}$ & 0.0009 & $<0.0001$ & 0.001 \\
\hline Lag time (h) & 0.008 & 0.021 & 0.020 & 0.018 & 0.010 & 0.0007 & 0.0001 & 0.021 & 0.020 & 0.015 & 0.007 & 0.0010 & $<0.0001$ & 0.458 \\
\hline $\operatorname{AGPR}(\mathrm{mL} / \mathrm{h})$ & 3.92 & 2.67 & 2.82 & 2.84 & 2.85 & 0.197 & 0.640 & 2.67 & 2.88 & 2.95 & 2.73 & 0.153 & 0.641 & 0.711 \\
\hline
\end{tabular}

Notes: ${ }^{\mathrm{a}, \mathrm{b}, \mathrm{c}}$ Means in a row without a common superscript letter differ within a subclass as the noted $p$-value; $\mathrm{NC}^{*}$ negative control fermentation of the hay-rich substrate without the inclusion of binder and aflatoxin $\mathrm{B} 1 ;{ }^{\dagger}$ fermentation of the hay-rich substrate without binder inclusion; ${ }^{\ddagger}$ standard error of least squares means; ${ }^{\S}$ statistical $p$-value estimated for the comparison between smectite clay and bamboo charcoal; ${ }^{\#}$ the nonlinear equation [17], GP (mL/g DM) $=\mathrm{GP}$ max $\times\left[1-\mathrm{e}^{-\mathrm{c} \times(\text { time }-\mathrm{Lag})}\right.$ ], was used to analyze the gas production kinetic data. $\mathrm{GP}_{\max }$, asymptotic gas production; c, gas production rate; Lag, lag phase before gas production commenced; AGPR, average gas production rate when half of the asymptotic gas volume was produced. 
Table 4. The effect of different doses of bamboo charcoal in comparison with smectite clay on aflatoxin B1 (AFB1) disappearance, mycotoxin recovery and fermentation characteristics in the cultures after a 72-h in vitro incubation of a hay-rich feed in the presence of $1.0 \mu \mathrm{g} / \mathrm{mL} \mathrm{AFB} 1$ (Experiment 2). VFA, volatile fatty acid.

\begin{tabular}{|c|c|c|c|c|c|c|c|c|c|c|c|c|c|c|}
\hline \multirow{2}{*}{ Items } & \multirow{2}{*}{ NC ${ }^{*}$} & \multicolumn{4}{|c|}{ Smectite clay } & \multirow{2}{*}{ SEM ${ }^{*}$} & \multirow{2}{*}{$p$-value } & \multicolumn{4}{|c|}{ Bamboo charcoal } & \multirow{2}{*}{ SEM * } & \multirow{2}{*}{$p$-value } & \multirow{2}{*}{ Contrast $^{\S}$} \\
\hline & & Control $^{\dagger}$ & $0.1 \mathrm{~g} / \mathrm{L}$ & $1 \mathrm{~g} / \mathrm{L}$ & $10 \mathrm{~g} / \mathrm{L}$ & & & Control $^{\dagger}$ & $0.1 \mathrm{~g} / \mathrm{L}$ & $1 \mathrm{~g} / \mathrm{L}$ & $10 \mathrm{~g} / \mathrm{L}$ & & & \\
\hline AFB1 disappearance $(\mu \mathrm{g} / \mu \mathrm{g})$ & - & $0.836^{\mathrm{c}}$ & $0.844^{\mathrm{c}}$ & $0.901^{\mathrm{b}}$ & $0.969^{\mathrm{a}}$ & 0.0073 & $<0.0001$ & $0.836^{\mathrm{b}, \mathrm{c}}$ & $0.818^{\mathrm{c}}$ & $0.862^{b}$ & $0.962^{\mathrm{a}}$ & 0.0092 & $<0.0001$ & $<0.0001$ \\
\hline AFB1 recovery $(\mu \mathrm{g} / \mu \mathrm{g})$ & - & 0.062 & 0.059 & 0.042 & 0.026 & 0.0112 & 0.186 & 0.062 & 0.068 & 0.055 & 0.043 & 0.0099 & 0.197 & 0.035 \\
\hline Final $\mathrm{pH}$ & 6.76 & 6.88 & 6.88 & 6.88 & 6.82 & 0.023 & 0.215 & 6.88 & 6.93 & 6.99 & 6.87 & 0.053 & 0.445 & 0.081 \\
\hline Ammonia N (mM) & 15.7 & 13.6 & 13.6 & 13.1 & 13.2 & 0.47 & 0.816 & 13.6 & 14.1 & 13.7 & 13.2 & 0.31 & 0.332 & 0.257 \\
\hline Total VFA ${ }^{\#}(\mathrm{mM})$ & 78.7 & 68.0 & 68.5 & 66.2 & 60.4 & 3.64 & 0.487 & $68.0^{\mathrm{b}}$ & $81.3^{\mathrm{a}}$ & $85.8^{\mathrm{a}}$ & $87.1^{\mathrm{a}}$ & 2.50 & 0.012 & $<0.0001$ \\
\hline Acetate $(\mathrm{mol} / 100 \mathrm{~mol})$ & 71.8 & $70.2^{\mathrm{a}}$ & $68.7^{\mathrm{a}, \mathrm{b}}$ & $68.0^{\mathrm{b}}$ & $67.2^{\mathrm{b}}$ & 0.59 & 0.025 & 70.2 & 70.3 & 69.0 & 68.8 & 0.57 & 0.184 & 0.001 \\
\hline Propionate (mol/100 mol) & 18.5 & $20.0^{c}$ & $21.7^{\mathrm{b}}$ & $22.1^{\mathrm{a}, \mathrm{b}}$ & $22.5^{\mathrm{a}}$ & 0.19 & $<0.0001$ & $20.0^{b}$ & $20.4^{\mathrm{b}}$ & $21.5^{\mathrm{a}}$ & $22.1^{\mathrm{a}}$ & 0.24 & 0.0004 & 0.0004 \\
\hline Butyrate (mol/100 mol) & 4.09 & 4.19 & 4.31 & 4.36 & 4.40 & 0.13 & 0.700 & 4.19 & 4.03 & 4.24 & 3.98 & 0.10 & 0.322 & 0.002 \\
\hline Iso-butyrate (mol/100 mol) & 0.74 & 0.71 & 0.78 & 0.73 & 0.82 & 0.026 & 0.227 & 0.71 & 0.75 & 0.76 & 0.76 & 0.020 & 0.974 & 0.263 \\
\hline Valerate $(\mathrm{mol} / 100 \mathrm{~mol})$ & 1.32 & 1.49 & 1.51 & 1.64 & 1.57 & 0.056 & 0.403 & 1.49 & 1.47 & 1.46 & 1.40 & 0.049 & 0.709 & 0.007 \\
\hline Iso-valerate (mol/100 mol) & 2.96 & 2.97 & 3.06 & 2.99 & 3.07 & 0.010 & 0.916 & 2.97 & 2.97 & 3.02 & 2.92 & 0.074 & 0.817 & 0.286 \\
\hline $\mathrm{NGR}^{\zeta}$ & 3.97 & $3.76^{\mathrm{a}}$ & $3.40^{\mathrm{b}}$ & $3.29^{\mathrm{b}}$ & $3.22^{\mathrm{b}}$ & 0.039 & 0.003 & $3.76^{\mathrm{a}}$ & $3.65^{\mathrm{a}, \mathrm{b}}$ & $3.44^{\mathrm{b}, \mathrm{c}}$ & $3.32^{\mathrm{c}}$ & 0.055 & 0.006 & 0.001 \\
\hline
\end{tabular}

Notes: ${ }^{\mathrm{a}, \mathrm{b}, \mathrm{c}}$ Means in a row without a common superscript letter differ within a subclass as the noted $p$-value; NC ${ }^{*}$ negative control fermentation of the hay-rich substrate without the inclusion of binder and AFB $1 ;{ }^{\dagger}$ fermentation of the hay-rich substrate without binder inclusion; ${ }^{*}$ standard error of least square means; ${ }^{\S}$ significant $p$-value for the comparison between smectite clay and bamboo charcoal; ${ }^{\#}$ total concentration of acetate, propionate, butyrate, iso-butyrate, valerate and iso-valerate; ${ }^{\zeta}$ ratio of non-glucogenic to glucogenic acids. 
The $\mathrm{pH}$ and ammonia $\mathrm{N}$ levels did not differ between binders and between dosages (Table 4). The total VFA concentration was lower in SC than $\mathrm{BC}(p<0.0001)$. The SC addition numerically decreased the total VFA concentration, whereas the $\mathrm{BC}$ addition treatments increased the total VFA concentration $(p=0.012)$. No differences in response to the addition of SC or BC occurred for molar proportions of butyrate, iso-butyrate, valerate or iso-valerate. The molar acetate proportion was decreased by SC compared to the control $(p=0.025)$, but it did not differ among $\mathrm{BC}$ additions. The molar acetate proportion was greater in $\mathrm{BC}$ than $\mathrm{SC}$ addition $(p=0.001)$. The molar propionate proportion was increased by both SC $(p<0.0001)$ and $\mathrm{BC}(p=0.0001)$, and it was greater in SC than $\mathrm{BC}(p=0.0004)$. Molar proportions of butyrate $(p=0.002)$ and valerate $(p=0.007)$ were lower in $\mathrm{BC}$ than SC. Consequently, the NGR value was decreased by the addition of SC $(p=0.003)$ or BC $(p=0.006)$, and it was greater in $\mathrm{BC}$ in comparison with $\mathrm{SC}(p=0.001)$.

\section{Discussion}

\subsection{AFB1 Adsorption by BC in Comparison with SC}

The adsorption capacity reflects the ability of a binder to adsorb AFB1 when the AFB1 was presented in a sufficient concentration. Physical methods are considered to be the most efficient way to reduce the toxicity of AFB1, in which smectite clays have been evaluated for their binding capacity and affinity for AFB1 [24-27]. The surface area, sodium:calcium ratio, porosity characteristics, the amount of smectite, the cation exchange capacity, the hydrated radius of the interlayer cations, the occurrence of $\mathrm{Fe}$ and/or $\mathrm{Mg}$ in the smectite structure, the amount of organic carbon and the hydrophobicity of the smectite surface in the clays may be involved in a complex way to bind aflatoxin [6,27-30]. The in vivo binding capacity of activated charcoal in different sources varied due to the variations in the surface area, although all of the activated charcoal bound over $95 \%$ of the aflatoxin in vitro [6]. Hydrated sodium aluminosilicate was regarded as one of the most widely used binders for AFB1 adsorption, and it exhibited strong AFB1-binding ability in vitro and in vivo. Duarte et al. [31] noted that the in vitro AFB1 binding capacity values of all HSCAS sequestering agents were greater than 95\%. Such high AFB1 binding capacity was observed for SC at a concentration of $10 \mathrm{~g} / \mathrm{L}$. Although activated charcoal was also widely used for its adsorption capacity and adsorption proportion for mycotoxin, the practical value of activated carbon as a feed additive might be limited by the fact that it also binds other nutrients, such as vitamins [32]. BC had a good capability for adsorbing dyes in wastewater, because it had larger pores than activated charcoal, allowing it to adsorb larger molecules [33]. In the present study, the binding ability of BC for AFB1 reached an equilibrium state after $3 \mathrm{~h}$, and it remained stable throughout the rest of the incubation period, with the same adsorption pattern as seen for SC. The overall AFB1 adsorption capacity and proportion were comparatively greater in BC than SC (Figure 1), suggesting that BC could be as effective as SC in adsorbing AFB1.

The adsorption proportion reflects the mycotoxin adsorption ability of a binder when the addition level of the binder is not limited, and its value is affected by the binder pore size and surface area, as well as the mycotoxin structure and concentration. The in vitro adsorption proportion of BC (average value $=0.955)$ in the present study (Figure 1 ) was remarkably greater than 0.673 , noted for the yeast 
cell extracts [34], and similar to the in vitro result of HSCAS [31], the adsorption capacity for HSCAS, which was also studied in an in vivo experiment, shows a higher binding capacity for AFB1 in feed and can reduce the AFB1 transmission from feed into milk [7]. The surface area and the water holding capacity are important factors affecting the binding capacity for AFB1. Regarding these factors in the above, BC maybe show a high binding capacity for AFB1 an in vivo experiment, because of the large surface area, the many pores and a high water holding [33], but the in vivo study results should be measured following in vitro evaluation to clarify if $\mathrm{BC}$ does or does not do not bind vitamins or minerals, otherwise the use of this absorbent in animal nutrition could be limited or not recommended.

\subsection{Disappearance of AFB1 in the Presence of BC in Comparison with SC}

Spotti et al. [10] developed an in vitro method to test the ability of sorbent materials to bind aflatoxin in $1 \mathrm{~mL}$ ruminal fluids incubated for $2 \mathrm{~h}$ at $39{ }^{\circ} \mathrm{C}$. With the application of these methods, the binders containing HSCAS, SC and clinoptilotile were proven to have different adsorption characteristics for binding AFB1, though the length of exposure to AFB1 might not be adequate to mimic rumen fermentation.

In the present study, batch cultures in Experiment 2 were conducted in a $75-\mathrm{mL}$ (rumen fluid: buffer $=1: 2$ ) ruminal system for in vitro mimicry of 72-h rumen fermentation, and the mycotoxin disappearance rate for AFB1 was 0.836 in the control without the addition of any binders (Table 4). Engel and Hagemeister [35] reported that $42 \%$ of AFB1 was degraded when incubated in vitro with rumen fluid. Westlake et al. [36] in their in vitro mycotoxin studies with rumen fluid reported that the degradation of AFB1 after $12 \mathrm{~h}$ was $<10 \%$ when added at levels of 1.0 and $10 \mu \mathrm{g} / \mathrm{mL}$ Forty-five percent of AFB1 was degraded when AFB1 at an initial concentration of $0.2 \mu \mathrm{g} / \mathrm{mL}$ was incubated at $39{ }^{\circ} \mathrm{C}$ in a $1-\mathrm{mL}$ fresh ruminal fluid system for $2 \mathrm{~h}$ [10]. All of these reported AFB1 disappearance rates were far lower than the value of 0.836 in the present study. These results imply that the ability of rumen microorganisms to reduce AFB1 toxicity might depend on the length of time of mycotoxin exposure for rumen microorganisms. The type of microbes in the rumen influenced by the species of animal and the types of forage fed for the animal would also affect the extent of the degradation of AFB1 [21]. Kiessling et al. [37] found that AFB1 and ochratoxin A were not well metabolized by whole rumen fluid, although mycotoxins zearalenone, T-2 toxin, diacetoxyscirpenol and deoxynivalenol were well metabolized. Westlake et al. [36] reported that Butyrivibrio fibrisolvens was able to degrade mycotoxins zearalenone, T-2 toxin, diacetoxyscirpenol and deoxynivalenol, but not AFB1. The results in the above suggested that the mycotoxin might disturb the growth and metabolic activity of rumen microorganisms, though the microbial population of the rumen plays a role in detoxification.

In the present study, AFB1 disappearance was increased by both $\mathrm{BC}$ and SC addition treatments with dosages greater than or equal to $1.0 \mathrm{~g} / \mathrm{L}$ compared to the control (Table 4). The average AFB1 disappearance was comparatively lower in the $\mathrm{BC}$ than in the SC addition treatment (0.881 vs. 0.904, $p<0.0001)$. The amount of AFB1, recovered from the pellet after the methanol washing procedure at $39{ }^{\circ} \mathrm{C}$ for $1 \mathrm{~h}$, could reflect the quantity of AFB1 that was not destroyed by rumen microorganisms, but had that been bound to the feed and binders in the system. Both the $\mathrm{BC}$ and $\mathrm{SC}$ addition treatments resulted in low AFB1 recovery values, especially for these binders added at $10 \mathrm{~g} / \mathrm{L}$ (Table 4), but comparatively higher AFB1 recovery values were observed for $\mathrm{BC}$ in comparison with $\mathrm{SC}(p=0.035)$, 
suggesting that the optimal binder dosage to reduce the detrimental effects of aflatoxin was different for BC compared to SC.

\subsection{In Vitro Ruminal Fermentation Responses to BC in Comparison with SC}

The in vivo digestibility of animal feeds can be estimated by measuring the in vitro gas production of feed samples incubated in ruminal fluid [17]. Westlake et al. [36] noted that AFB1 inhibited microbial digestion of lucerne hay incubated with bacterial, protozoal and ovine ruminal fluid preparations. In the present study, both SC and BC addition treatments increased IVDMD, cumulative gas production at $72 \mathrm{~h}$ and asymptotic gas production (Table 3), suggesting that both binders indeed had the ability to reduce the detrimental effects of AFB1 on microbial digestion. The addition of binder reduced the lag time of the fermentation, and asymptotic gas production was greater in the $\mathrm{BC}$ than in the $\mathrm{SC}$ addition treatments, suggesting that $\mathrm{BC}$ could be more effective for reducing the detrimental effect of AFB1 on rumen fermentation than $\mathrm{SC}$, due to the larger pore size and the greater number of pores in BC compared to SC.

In the present study, binder dosage did not alter ammonia $\mathrm{N}$ concentration, and no differences were observed for ammonia $\mathrm{N}$ concentration between $\mathrm{SC}$ and $\mathrm{BC}$. In the rumen, the feed protein is usually hydrolyzed and deaminated, forming peptides and free ammonia by the rumen microorganisms [38]. If the digestion and metabolism of feed protein were inhibited by AFB1, the concentration of free ammonia would be decreased. In the present study, then, ammonia $\mathrm{N}$ concentrations in both SC and $\mathrm{BC}$ were lower than the control without any inclusions of AFB1 and binder, suggesting that the method of hydrolysis or deamination of the protein was decreased by the presence of AFB1 regardless of the binder added. A decrease of ammonia production was also observed for AFB1 ingestion at $0.2-0.8 \mathrm{mg} / \mathrm{kg}$ body weight in acute bovine aflatoxicosis [39].

The production of VFAs can account for over two-thirds of the energy intake in a host ruminant animal [40], and therefore, VFAs, resulting from rumen fermentation, can be regarded as an important index for fermentation efficiency. In the literature, no differences of total VFA concentration in the rumen were observed in growing lambs [41] fed $2.5 \mathrm{mg}$ AFB1 per $\mathrm{kg}$ diet, steers [38] fed $60-600 \mu \mathrm{g} / \mathrm{kg}$ diet and lactating goats [42] daily fed $0.714 \mu \mathrm{mol}$ AFB1. On the contrary, VFA production was decreased by AFB1 at $0.2-0.8 \mathrm{mg} / \mathrm{kg}$ body weight in acute bovine aflatoxicosis [39]. Regardless of the binder added, the total VFA concentration was lower in both the SC and BC groups than in the control without any inclusions of AFB1 and binder, suggesting that AFB1 present in the culture fluids decreased the growth and metabolic activity of rumen microorganisms. With the increase of the binder dose, the total VFA concentration markedly increased in the $\mathrm{BC}$ treatment, while it numerically decreased in SC, suggesting that BC indeed reduced the adverse effects of AFB1 on rumen microbial activity.

The balance between the supplies of glucogenic relative to non-glucogenic fatty acids influences the efficiency of VFA utilization for different productive purposes in ruminant animals. The observed VFA pattern and the occurrence of high NGR values for BC addition treatments (Table 4) imply that the addition of $\mathrm{BC}$ in comparison with $\mathrm{SC}$ would result in greater stimulation of the production of glucogenic acids (especially propionate) in the rumen as precursor nutrients for the host animal. 


\section{Conclusions}

An equilibrium mycotoxin adsorption test showed that bamboo charcoal had a comparatively higher adsorption capacity for aflatoxin B1 (AFB1) than a smectite clay. Relative to the smectite, bamboo charcoal increased feed digestibility, gas and volatile fatty acid production, which reduced the detrimental effects of AFB1 on rumen fermentation. This study compared bamboo charcoal and a smectite in sequestering AFB1 and demonstrated that bamboo charcoal can bind AFB1 as effectively as smectite under the occurrence of microbial aflatoxin degradation.

\section{Acknowledgments}

This work was supported by funds from National Science and Technology Support Program of the Ministry of Science and Technology of China (Project No. 2012BAD29B07). The authors acknowledge Peter Lund, Department of Animal Science, Research Centre Foulum, Aarhus University, for providing language help and for proof reading the manuscript.

\section{Author Contributions}

Ya-Hui Jiang and Ping Wang conducted the experiment and completed manuscript writing after conceiving Hong-Jian Yang's idea development in the experimental design; Both Hong-Jian Yang and Ying Chen contributed to interpretation of data and overall revision of manuscript.

\section{Conflicts of Interest}

The authors declare no conflict of interest.

\section{References}

1. Diekman, M.A.; Green, M.L. Mycotoxins and reproduction in domestic livestock. J. Anim. Sci. 1992, 70, 1615-1627.

2. Van Egmond, H.P. Aflatoxin M1: Occurrence, toxicity, regulation. In Mycotoxins in Dairy Products; Van Egmond, H.P., Ed.; Elsevier Applied Science: London, UK, 1989; pp. 11-55.

3. Veldman, A.; Meijst, J.A.C.; Borggreve, G.J.; Heeres-van Tol, J.J. Carry-over of aflatoxin from cow's food to milk. Anim. Prod. 1992, 55, 163-168.

4. Fink-Gremmels, J. Mycotoxins in cattle feeds and carry-over to dairy milk: A review. Food Addit. Contam. Part A Chem. Anal. Control Expo. Risk Assess. 2008, 25, 172-180.

5. Samarajeewa, U.; Sen, A.C.; Cohen, M.D.; Wei, C.I. Detoxification of aflatoxins in foods and feeds by physical and chemical methods. J. Food Prot. 1990, 53, 489-501.

6. Huwig, A.; Freimund, S.; Kappeli, O.; Dutler, H. Mycotoxin detoxification of animal feed by different adsorbents. Toxicol. Lett. 2001, 122, 179-188.

7. Diaz, D.E.; Hagler, W.M., Jr.; Blackwelder, J.T.; Eve, J.A.; Hopkins, B.A.; Anderson, K.L.; Jones, F.T.; Whitlow, L.W. Aflatoxin Binder II: Reduction of aflatoxin M1 in milk by sequestering agents of cows consuming aflatoxin in feed. Mycopathologia 2004, 157, 233-241. 
8. Kittinaovarat, S.; Suthamnoi, W. Physical properties of polyolefin/bamboo charcoal composites. J. Met. Mater. Miner. 2009, 19, 9-15.

9. Lemke, S.L.; Ottinger, S.E.; Mayura, K.; Ake, C.L.; Pimpukdee, K.; Wang, N.; Phillips, T.D. Development of a multi-tiered approach to the in vitro prescreening of clay-based enterosorbent. Anim. Feed Sci. Technol. 2001, 93, 17-29.

10. Spotti, M.; Fracchiolla, M.L.; Arioli, F.; Caloni, F.; Pompa, G. Aflatoxin B1 binding to sorbents in bovine ruminal fluid. Vet. Res. Commun. 2005, 29, 507-515.

11. Jiang, Y.H.; Yang, H.J.; Lund, P. Effect of aflatoxin B1 on in vitro ruminal fermentation of ratio high in alfalfa hay or ryegrass hay. Anim. Feed Sci. Technol. 2012, 175, 85-89.

12. Ramos, A.J.; Fink-Gremmels, J.; Hernandez, E. Prevention of toxic effects of mycotoxins by means of non-nutritive adsorbent compounds. J. Food Prot. 1996, 59, 631-641.

13. Menke, K.H.; Steingass, H. Estimation of the energetic feed value obtained from chemical analysis and in vitro gas production using rumen fluid. Anim. Res. Dev. 1988, 28, 7-55.

14. Vekiru, E.; Fruhauf, S.; Sahin, M.; Ottner, F.; Schatzmayr, G.; Krska, R. Investigation of various adsorbents for their ability to bind Aflatoxin B1. Mycotoxin Res. 2007, 23, 27-33.

15. Jaynes, W.F.; Zartman, R.E.; Hudnall, W.H. Aflatoxin B1 adsorption by clays from water and corn meal. Appl. Clay Sci. 2007, 36, 197-205.

16. Zhang, D.F.; Yang, H.J. In vitro ruminal methanogenesis of a hay-rich substrate in response to different combination supplements of nitrocompounds, pyromellitic diimideand, 2-bromoethanesulphonate. Anim. Feed Sci. Technol. 2011, 163, 20-32.

17. France, J.; Dijkstra, J.; Dhanoa, M.S.; López, S.; Bannink, A. Estimating the extent of degradation of ruminant feeds in vivo from a description of their gas production profiles observed in vitro: Derivation of models and other mathematical considerations. Br. J. Nutr. 2000, 83, 143-150.

18. García-Martínez, R.; Ranilla, M.J.; Tejido, M.L.; Carro, M.D. Effects of disodium fumarate on in vitro rumen microbial growth, methane production and fermentation of diets differing in their forage: Concentrate ratio. Br. J. Nutr. 2005, 94, 71-77.

19. Official Methods of Analysis, 16th ed.; Association of Official Analytical Chemists: Washington, DC, USA, 1999.

20. Van Soest, P.J.; Robertson, J.B.; Lewis, B.A. Methods for dietary fibre, neutral detergent fibre and non-starch polysaccharides in relation to animal nutrition. J. Dairy Sci. 1991, 74, 3583-3597.

21. Upadhaya, S.D.; Sung, H.G.; Lee, C.H.; Lee, S.Y.; Kim, S.W.; Cho, K.J.; Ha, J.K. Comparative study on the aflatoxin B1 degradation ability of rumen fluid from Holstein Steers and Korean native goats. J. Vet. Sci. 2009, 10, 29-34.

22. Verdouw, H.; Van Echteld, C.J.A.; Dekkers, E.M.J. Ammonia determination based on indophenol formation with sodium salicylate. Water Res. 1978, 12, 399-402.

23. Ørskov, E.R. Manipulation of rumen fermentation for maximum food utilization. World Rev. Nutr. Diet. 1975, 22, 152-182.

24. Dixon, J.B.; Kannewischer, I.; Arvide, M.G.T.; Velazquez, A.L.B. Aflatoxin sequestration in animal feeds by quality-labeled smectite clays: An introductory plan. Appl. Clay Sci. 2008, 40, 201-208. 
25. Harvey, R.B.; Phillips, T.D.; Ellis, J.A.; Kubena, L.F.; Huff, W.E.; Petersen, D.V. Effects of aflatoxin M1 residues in milk by addition of hydrated sodium calcium aluminosilicate to aflatoxin-contaminated diets of dairy cows. Am. J. Vet. Res. 1991, 52, 1556-1559.

26. Ramos, A.J.; Hernandez, E. In vitro aflatoxin adsorption by means of a montmorillonite silicate. A study of adsorption isotherms. Anim. Feed Sci. Technol. 1996, 62, 263-269.

27. Dvorak, M. Ability of bentonite and natural zeolite to adsorb aflatoxin from liquid media. Vet. Med. Praha 1989, 34, 733-741.

28. Arvide, M.G.T.; Mulder, I.; Velazquez, A.L.B.; Dixon, J.B. Smectite clay adsorption of aflatoxin versus octahedral composition, as indicated by FTIR. Clays Clay Miner. 2008, 56, 571-578.

29. Jaynes, W.F.; Zartman, R.E. Influence of soluble feed proteins and clay additive charge density on aflatoxin binding in ingested feeds. In Aflatoxins-Biochemistry and Molecular Biology; Guevara-Gonzalez, R.G., Ed.; InTech.: Rijeka, Croatia, 2011; ISBN: 978-953-307-395-8. Available online: http://www.intechopen.com/books/aflatoxins-biochemistryand-molecular-biology/ influence-of-soluble-feedproteins-and-clay-additive-chargedensity-on-aflatoxin-binding-in-ingested (accessed on 5 October 2011).

30. Carraro, A.; De Giacomo, A.; Giannossi, M.L.; Medici, L.; Muscarella, M.; Palazzo, L.; Quaranta, V.; Summa, V.; Tateo, F. Clay minerals as adsorbents of aflatoxin M1 from contaminated milk and effects on milk quality. Appl. Clay Sci. 2013, 88-89, 92-99.

31. Duarte, E.D.; Winston, M.H.J.; Brinton, A.H.; Lon, W.W. Aflatoxin binders I: In vitro binding assay for aflatoxin B1 by several potential sequestering agents. Mycopathologia 2002, 156, 223-226.

32. Galvano, F.; Pietri, A.; Bertuzzi, T.; Fusconi, G.; Galvano, M.; Piva, A.; Piva, G. Reduction of carryover of aflatoxin from cow feed to milk by addition of activated carbons. J. Food Prot. 1996, 59, 551-554.

33. Kim, B.C.; Kim, Y.H.; Yamamoto, T. Adsorption characteristics of bamboo activated carbon. Korean J. Chem. Eng. 2008, 25, 1140-1144.

34. Li, J.J.; Suo, D.C.; Su, X.O. Binding capacity for aflatoxin B1 by different adsorbents. Agric. Sci. Chin. 2010, 9, 449-456.

35. Engel, V.G.; Hagemeister, H. Untersuchungenueber denverblieb von aflatoxin B1 im Verdaaundtarkt von Kuehen. In Biological Detoxification of Fungal Toxin and its use in Plant Breeding, Feed and food production. Nat. Toxins 1999, 7, 1-23.

36. Westlake, K.; Mackie, R.I.; Dutton, M.F. In vitro metabolism of mycotoxins by bacterial, protozoal and ovine ruminal fluid preparations. Anim. Feed Sci. Technol. 1989, 25, 169-178.

37. Kiessling, K.H.; Pettersson, H.; Sandholm, K.; Olsen, M. Metabolism of aflatoxin, ochratoxin, zearalenone, and three trichothecenes by intact rumen fluid, rumen protozoa, and rumen bacteria. Appl. Environ. Microbiol. 1984, 47, 1070-1073.

38. Reynal, S.M.; Ipharraguerre, I.R.; Lin eiro, M.; Brito, A.F.; Broderick, G.A.; Clark, J.H. Omasal flow of soluble proteins, peptides and free amino acids in dairy cows fed diets supplemented with proteins of varying ruminal degradabilities. J. Dairy Sci. 2007, 90, 1887-1903.

39. Cook, W.O.; Richard, J.L.; Osweiller, G.D.; Trampel, D.W. Clinical and pathologic changes in acute bovine aflatoxicosis: Rumen motility and tissue and fluid concentrations of aflatoxins B1 and M1. Am. J. Vet. Res. 1986, 47, 1817-1825. 
40. Bergman, E.N. Glucose metabolism in ruminants as related to hypoglycemia and ketosis. Am. J. Physiol. 1973, 215, 865-873.

41. Edrington, T.S.; Harvey, R.B.; Kubena, L.F. Effect of aflatoxin in growing lambs fed ruminally degradable or escape protein sources. J. Anim. Sci. 1994, 72, 1274-1281.

42. Helferich, W.G.; Garrett, W.N.; Hsieh, D.P.H.; Baldwin, R.L. Feedlot performance and tissue residues of cattle consuming diets containing aflatoxins. J. Anim. Sci. 1986, 62, 691-696.

(C) 2014 by the authors; licensee MDPI, Basel, Switzerland. This article is an open access article distributed under the terms and conditions of the Creative Commons Attribution license (http://creativecommons.org/licenses/by/3.0/). 